prof. dr hab. inz. Jerzy Madej,

dr hab. inz. Marian Medwid prof. nadzw.,

dr Wtodzimierz Stawecki prof. nadzw.

Instytut Pojazdów Szynowych „TABOR”

\title{
Konstrukcja newralgicznych węzlów wózka krańcowego w module naczep drogowych w uformowaniu kolejowym
}

\begin{abstract}
$W$ artykule zaprezentowano rozwiazania konstrukcyjne newralgicznych elementów pozycjonujacych i mocujących ramy kolejowego wózka krańcowego i naczepy drogowej w obrębie transportowego modutu naczep bimodalnych. Referat nawiqzuje do prowadzonych analiz koncepcyjnych $w$ wyniku realizacji projektu rozwojowego NR R10-0065-10 „System transportu naczep drogowych na wózkach kolejowych w kombinowanym ruchu kolejowo-drogowym".
\end{abstract}

\section{MERYTORYCZNY ZAKRES ARTYKULU}

Kolejowy przewóz naczep drogowych jest znany od kilkudziesięciu już lat i coraz częściej stosowany w nowoczesnych zarządach transportu towarów. Jest to tzw. transport multimodalny, w szczególnym zastosowaniu znany szeroko jako bimodalny system transportowy, który w uformowaniu kolejowym odbywa się $\mathrm{w}$ infrastrukturze torowej na specjalnych wózkach kolejowych. Poszczególne rozwiązania w obrębie rozległego systemu transportu bimodalnego różnią się w szczegółach konstrukcyjnych, przy czym każde $\mathrm{z}$ tych rozwiązań stosuje specjalne wózki kolejowe, na których spoczywa każda naczepa drogowa, oparta zarówno w strefie swego drogowego „przodu”, jak też drogowego „tyłu”.

Na rysunku 1 zilustrowano podjazd (wpychanie) czołowego wózka kolejowego pod naczepę drogowa, co stanowi jedną z faz wielofazowej operacji formowania kolejowego składu naczep do przewozu na szlaku kolejowym.

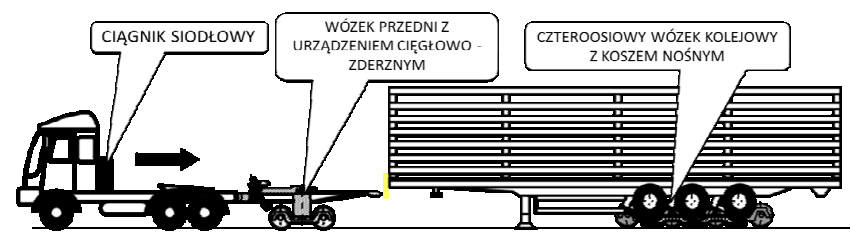

Rys. 1 - Podjazd kolejowego wózka czołowego pod przód naczepy drogowej

Po wepchnięciu wózka pod naczepę za pomocą ciągnika drogowego, należy ręcznie połączyć ramę naczepy drogowej z ramą czołowego wózka kolejowego. Sztywne i niezawodne połączenie ramy naczepy drogowej z ramą czołowego wózka kolejowego, na którym spoczywa przednia część naczepy, jest bardzo istotne, gdyż naczepa drogowa w uformowaniu kolejowym musi przenosić znaczne wartości sił trakcyjnych, właściwych warunkom ruchowym pociagu kolejowego. Należy przy tym zapewnić należyte bezpieczeństwo pracy personelu przygotowujacego skład naczep drogowych do kolejowego ruchu w torze. $\mathrm{Z}$ tej przyczyny sposób połączenia kolejowego wózka krańcowego z ramą naczepy drogowej powinien zapewniać precyzję wzajemnego pozycjonowania elementów ram naczepy i wózka przy możliwie dużym zakresie samoczynnego naprowadzania zmechanizowanego (według rys. 1), oraz całkowicie eliminować konieczność wchodzenia pracownika pod naczepę dla dokonania jakichkolwiek czynności ryglowania lub zabezpieczania przed przesunięciem czy też rozłączeniem podczas ruchu składu naczep w torze. Oznacza to, że wszystkie konieczne czynności manualne (ryglowanie oraz zabezpieczanie przed rozłączeniem) powinny być dokonywane przez pracownika operującego $\mathrm{w}$ pozycji stojącej, z boku naczepy, przy użyciu niewielkiego wysiłku fizycznego.

Na rysunku 2 przedstawiono skład bimodalny uformowany w trójnaczepowy moduł transportowy.

Zgodnie $\mathrm{z}$ rysunkiem 2, kolejowe urządzenia cięgłowo - zderzne znajdują się jedynie na krańcach transportowego modułu naczep drogowych w uformowaniu kolejowym. Każda naczepa 1, w transportowym uformowaniu kolejowym, jest oparta w części przedniej na wózkach kolejowych krańcowych 2, (wyposażonych $\mathrm{w}$ kolejowe urzązenia cięgłowo zderzne) oraz - zależnie od jej miejsca w module - na wózkach międzynaczepowych 3 (bez takich urządzeń). Widzimy więc, że pozycjonowanie i mocowanie ram wózków 2 i 3 względem ram naczep drogowych ma zasadnicze znaczenie dla zapewnienia po- 


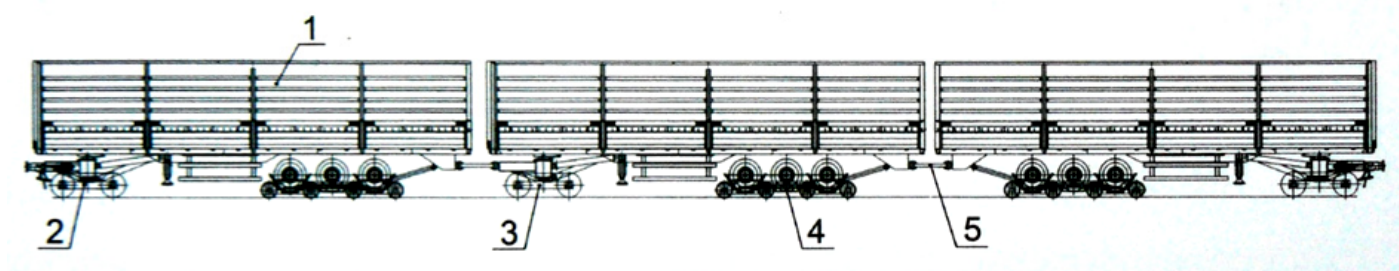

Rys. 2 - Trójnaczepowy moduł transportowy naczep drogowych przygotowany do ruchu w składzie pociągu towarowego; konstrukcyjna wersja wyjściowa (A), początkowa

prawnego ruchu tych wózków w torze. W konstrukcyjnych projektach wózków 2 i 3 należy więc uwzględnić następujące czynniki:

- łatwość formowania składu naczep drogowych w kolejowe moduly transportowe w obrębie terminala

- precyzje i niezawodność mocowania ram krańcowych wózków kolejowych do ram naczep drogowych

- bezpieczeństwo operacji formowania składu i manualną łatwość mocowania ram wózków do ram naczep.

Niniejszy artykuł szczegółowo dotyczy jedynie początkowej (wyjściowej) struktury (A) kolejowego modułu transportowego naczep drogowych, w której wszystkie podłużne składowe trakcyjnych sił kolejowych obciążaja ramy naczep. W trakcie prac nad tematem wyłoniła się też struktura (B) rozwojowa, w której ramy kolejowo uformowanych naczep są podłużnie obciążone jedynie siłami bezwładności własnej, natomiast kolejowe siły trakcyjne obciążają podłużnie wyłącznie część kolejową systemu modułowego. Tę rozwojową strukturę przedstawiono na rysunku 3, w przykładowej formie modułu dwunaczepowego.

Porównując rysunki 2 i 3 widzimy, że projekt konstrukcyjny wózka krańcowego w obydwóch wersjach ma do spełnienia identyczne zadanie odnośnie precyzji kątowego pozycjonowania i niezawodności podłużnego mocowania ramy wózka kolejowego względem ramy naczepy drogowej.

\section{NEWRALGICZNE WEZLY KONSTRUK- CYJNE WÓZKA KRAŃCOWEGO}

Zgodnie z powyższymi uwagami, jako operacyjnie newralgiczne węzły wózka krańcowego należy traktować zarówno samonaprowadzające się kliny i gniazda pozycjonujące połączenia kolejowego wózka czołowego z ramą naczepy drogowej, jak też śrubowe rygle hakowe umieszczone tak, że wchodzenie pracownika w obręb skrajni taboru nie jest konieczne.

Obiekt naszego zainteresowania został kolejno przedstawiony na przykładowych rysunkach, dotyczących szczegółowo struktury wyjściowej (A), przy czym rys. 4 przedstawia boczny widok wózka czołowego przygotowanego do osadzenia pod naczepą drogowa, rys. 5 przedstawia schemat połączenia ramy wózka $\underline{\mathbf{W}}$ z ramą naczepy $\underline{\mathbf{D}}$, w widoku bocznym, zaś rys. 6 - przedstawia widok kolejowego wózka czołowego z góry, na którym grubą linią przerywaną pokazano gabarytowy zarys ramy naczepy drogowej z gniazdami dla prowadników klinowych.

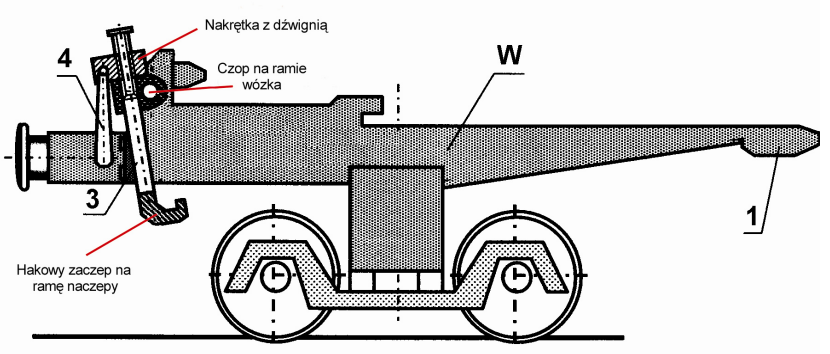

Rys. 4 - Boczny widok schematyczny wózka czołowego modułowej struktury (A), przygotowanego do osadzenia pod ramą bimodalnej naczepy drogowej

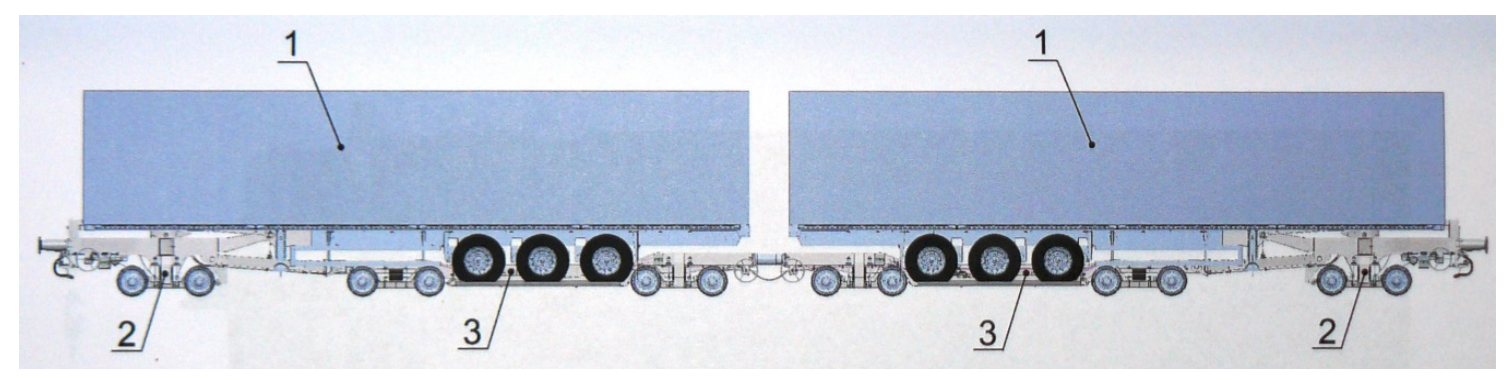

Rys. 3 Dwunaczepowy moduł transportowy naczep drogowych przygotowany do ruchu w składzie pociagu towarowego; konstrukcyjna wersja rozwojowa (B) 
Rysunek 4 dość szczegółowo ilustruje złożony przekrój podłużny wózka i naczepy, ukazując zarówno samonaprowadzające się kliny $\underline{\mathbf{1}}$ jak też gniazda $\underline{\mathbf{2}}$ w ramie naczepy, zapewniające pozycjonująca poprawność wzajemnego położenia ramy naczepy drogowej względem ramy wózka kolejowego, jak też śrubowe rygle hakowe $\underline{\mathbf{3}}$, wymagające ręcznego osadzenia w otworach $\underline{\mathbf{5}}$ ramy i skręcenia zespołu elementów na sztywno.

Trzy najazdowe, zbieżne kliny $\underline{1}$ ramy wózka, wsuwane do gniazd $\underline{\mathbf{2}} \mathrm{w}$ ramie naczepy, (jedno gniazdo środkowe pod naczepą i dwa boczne w części czołowej), zapewniające poprawność wzajemnego położenia i sztywność połączenia, powinny być wymiarowo dość ściśle tolerowane. Dla dopełnienia sztywności przyłączenia ramy wózka kolejowego do ramy naczepy drogowej należy podłużnie spiąć $\mathrm{z}$ ramą naczepy dwa rygle śrubowe $\underline{\mathbf{3}}$ posadowione wahliwie na obydwóch bokach czołowej części ramy wózka kolejowego $\underline{\mathbf{W}}$.

Oznaczenia na rysunkach:

$\underline{\mathbf{1}}$ - Samonaprowadzający się klin ramy wózka $\underline{\mathbf{W}}$

$\underline{\mathbf{2}}$ - Gniazdo osadzenia klina w ramie naczepy drogowej

$\underline{\mathbf{3}}$ - Śrubowy rygiel hakowy spinacza ramy naczepy z ramą wózka kolejowego

$\underline{4}$ - pokrętło śrubowego rygla hakowego $\underline{\mathbf{3}}$

$\underline{\mathbf{5}}$ - otwór dla osadzenia ryglującego haka $\underline{\mathbf{3}} \mathrm{w}$ ramie naczepy.

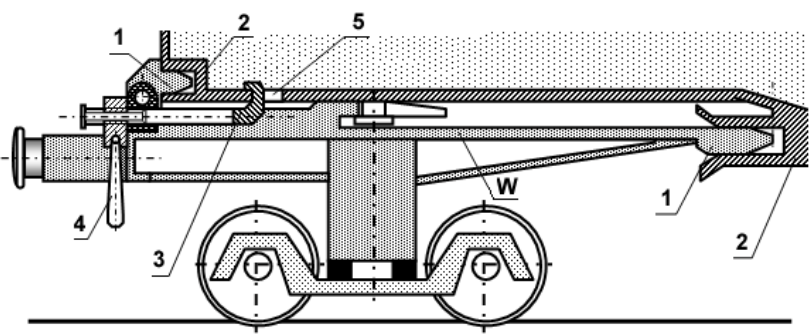

Rys. 5 - Schemat połączenia ramy wózka $\underline{\mathbf{W}}$ z ramą naczepy, widok boczny. Dotyczy struktury szczegółowej (A)

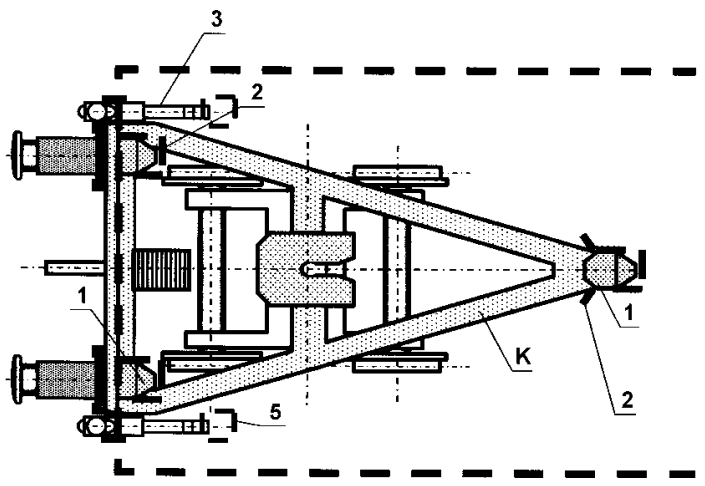

Rys. 6 - Widok kolejowego wózka czołowego z góry, na którym grubą linią przerywaną pokazano gabarytowy zarys ramy naczepy drogowej z gniazdami dla prowadników klinowych

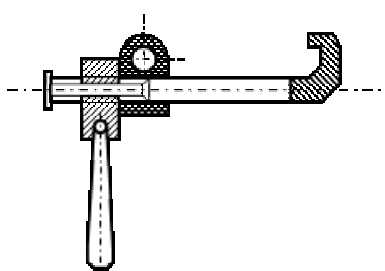

Rys. 7 - Spinacz $\underline{\mathbf{3}}$ ram z ryglem śrubowym zaciskanym pod ramą naczepy ręcznie z boku wózka kolejowego, w jego części czołowej.

\section{PODSUMOWANIE}

Projekt rozwiązań konstrukcyjnych węzłów mocowania ramy wózka krańcowego, wyposażonego w kolejowe urządzenia czołowo-zderzne, zawiera wypróbowane $\mathrm{w}$ kolejnictwie elementy śrubowo hakowe (spinacze) a zarazem nie wymaga od obsługi wchodzenia w obszar skrajni taboru.

Jednakże ewentualne zastosowanie wersji rozwojowej (B) - według rys. 3, wymagałoby dalszych prac nad opracowaniem bezpiecznego podłużnego połączenia ramy wózka krańcowego $\mathrm{z}$ ramą kolejowego wózka nośnego tyłu naczepy bez konieczności wchodzenia obsługi pod naczepę.

\section{Bibliografia}

[1] Zgłoszenie patentowe: Sposób połqczenia kolejowego wózka czołowego z rama naczepy drogowej.

[2] De Iorio, Antonio \& others: Fast connection system of decomposable structures of freight train for bi-modal transport; Journal of Rail and Rapid Transit 2012.

[3] Madej J., Medwid M.: Sprawozdanie merytoryczne z realizacji projektu rozwojowego NR 10-0065-10 pt: System transportu naczep drogowych na wózkach kolejowych $w$ kombinowanym ruchu kolejowo-drogowym. Poznań 2013. Archiwum IPS , Tabor”.

[4] Madej J., Medwid M., Cichy R., Jakuszko W., Nowaczyk T.: Modułowy system transportu naczep siodtowych na wózkach kolejowych w ruchu kombinowanym kolejowo-drogowym. XX Międzynarodowa Konferencja Naukowa „Pojazdy Szynowe 2012”-Poznań.

[5] Nowaczyk T.: Wybrane charakterystyki transportu intermodalnego (szynowo-drogowego). Praca magisterska NR TRM/S-11/2009.

[6] Medwid M., Cichy R., Nowaczyk T.: Model strukturalny systemu transportu naczep drogowych na wózkach kolejowych w ruchu kombinowanym kolejowo-drogowym. Pojazdy Szynowe nr 2/2011. Wydawnictwo IPS ,,Tabor” Poznań.

[7] Nowaczyk T., Medwid M., Jakuszko W.: Technologia przeładunku poziomego na przykładzie modułowego systemu transportu kombinowanego. XIV Międzynarodowa Konferencja Naukowa ,QSET 2013”- Niepołomice.

[8] Tomaszewski F., Medwid M., Nowaczyk T. Czerwiński J.: Cechy charakterystyczne modulowego systemu transportu naczep drogowych $w$ ruchu kolejowym $w$ odniesieniu do znanych systemów transportowych $w$ ruchu intermodalnych kolejowo-drogowych. Materiaty konferencyjne XI Konferencji naukowej Pojazdy Szynowe. Wrocław 2014. 